\title{
Eradicating information poverty: an agenda for research.
}

\author{
MARCELLA, R. and CHOWDHURY, G.
}

2020

Copyright (C) 2018 The Authors. Reprinted by permission of SAGE Publications. 


\title{
Eradicating information poverty: an agenda for research
}

\author{
Rita Marcella and Gobinda Chowdhury
}

\subsection{Introduction and rationale}

Information poverty has been a focus for information scientists over the last 50 years. There have been concerns around concepts of the information rich and the information poor and the chasm between the life experience of people on each side of the technology divide. It is possible to be excluded from access to sources of information as a result of (i) technological barriers; (ii) educational barriers; (iii) cultural barriers; (iv) language barriers; and (v) political barriers. Have these challenges been overcome? Fundamentally they still exist: although humans seem never to have had readier and more equitable access to information, in reality many of the most extreme forms of disadvantage are as pertinent and evident today as they were 50 years ago. Information poverty persists and casts a corrosive pall on people's access to opportunities, despite the fact that access to information has been increasingly seen as a fundamental human right.

In late January 2018, Donna Scheeder made the case to the U.N. that 'libraries lead in the war on information poverty', emphasising the continuing need for impoverished and excluded individuals to have free access to information as well as opportunities to gain the skills and knowledge necessary to find and apply information: 'there is no truly sustainable development without access to information, and no meaningful, inclusive access to information without libraries' (Scheeder, 2018, n.p). Chowdhury and Koya (2017) identify over 30 information related themes that are embedded in the U.N.'s sustainable development goals (SDCs) policy documents, evidencing the key role that access to information has in building stronger economies. Work on the Global Libraries Initiative also reinforces the extent to which information poverty continues to be a priority for international development organisations (Sawaya et al, 2011). Sadly, however, that programme will be concluded in 2018 , with only a legacy element to continue.

We have all heard the much-repeated refrain - information is power - but what does it really mean and what is the corollary in terms of understanding both how information can empower and what it means to be disenfranchised through lack of access to information? There is still a lack of evidence of the ways in which access to reliable information can empower and this paper seeks to reflect on where we are today through: (i) mapping key factors or contributors to information poverty; (ii) gathering views and opinions from a group of LIS academics about the current status and future potential for information poverty research; and (iii) beginning to populate a framework for information and library research to contribute in an impactful manner to the societal challenge of information 
poverty. It reviews previous research into information poverty and sets out the themes that emerged from a discussion held amongst LIS researchers in 2017 around the topic, which sought to understand how participants construed information poverty, its various manifestations, how the concept of information poverty related to existing research and priorities for future collaborative and interdisciplinary research.

\subsection{Literature Review}

\subsection{Definitions}

Poverty - The Joseph Rowntree Foundation (2018) provide a helpful definition of poverty, 'when your resources are well below your minimum needs' and a threefold categorisation of poverty in the West in 2017: (i) below minimum income standard but getting by; (ii) in poverty but not destitute; and (iii) destitute. The equalities protected characteristics also offer a helpful lens through which to think about particularly disadvantaged groups (Citizens Advice, 2018).

Disadvantage - One way of conceptualising information poverty is to think about what constitutes poverty or disadvantage in society today. We might define disadvantage as, lacking what the United Nations (U.N., 1948) describes in the Universal Declaration of Human Rights (Article 25) as 'a standard of living adequate for the health and well-being of himself and his family, including food, clothing, housing and medical care and necessary social services, and the right to security in the event of unemployment, sickness, disability, widowhood, old age or other lack of livelihood in circumstances beyond his control.' Disadvantage might include lack of the basic necessities of life, such as food, water, health care, proper housing, educational opportunities, job security, adequate medical care and so on. Those who are disadvantaged might generically be described as the poor, underprivileged, impoverished, deprived; handicapped, impaired, disabled or challenged.

Information poverty - Mayer (2003) tells us that 'the concept of "disadvantaged" was focused on "denied access to the tools needed for self-sufficiency."'. Among the tools necessary for self-sufficiency in a disadvantaged group, Meyer includes 'information people need to know about opportunities and tools available to them, and to know how to use them to effect their own, and their group's, development'. Meanwhile Britz (2004, p. 194) defined information poverty as 'that situation in which individuals and communities, within a given context, do not have the requisite skills, abilities or material means to obtain efficient access to information, interpret it and apply it appropriately'.

Vulnerable groups - In the U.K. the 2010 Equalities Act identified the following protected characteristics: age; disability; gender reassignment; marriage or civil partnership (in employment only); pregnancy and maternity; race; religion or belief; sex; sexual orientation. If an individual is treated unfairly because they belong to a group of people with protected characteristics, this is unlawful discrimination (Citizens Advice, 2018).

This paper adopts the following definition of information poverty: denied access to the information necessary for survival, self-sufficiency, sustainability or development. The 
factors underpinning this denial of access are wide ranging and emerge in the findings that follow.

\subsection{I nformation poverty research}

Deep seated notions of information poverty and information deficit, of the information rich and the information poor (see, for example, Yu, 2006 and Yu et al, 2016), have pervaded librarianship and information science research for more than 50 years (Haider and Bawden, 2007), while researchers in information behaviour have explored information as an empowering agent, in terms of the ways in which access to and use of information can assist individuals to overcome obstacles, take advantage of the opportunities available to them and improve their lives. Such research has explored the ways in which the concept of information poverty is morphing and is not necessarily synonymous with poverty in its socioeconomic sense (Yu et al., 2016). LIS research in this domain inter-relates with other disciplinary approaches, in political science, education and health. Its central theme is our understanding of information as an empowering and enfranchising agent and how user information behaviour and literacy - both information and digital literacy - impact information poverty. This crosscutting theme was inspired initially by the work of Dervin in the 1970s (see, for example, Dervin, 1980), in communications studies, on gaps and inequities in user access to information, and Chatman who inspired others to research what she called "the impoverished life-world of outsiders" (Chatman, 1996, book title). Chatman focused on exploring the information landscape of the poor or disadvantaged, while also considering those users who might face social, rather than economic, barriers to information.

However, pre-dating both of these, Childers and Post (1975) produced a valuable bibliography listing over 700 items emanating from library and information science research which cast light on what the authors termed the information universe of disadvantaged adults. By the 1980s a range of researchers had touched on aspects of information poverty, including work by Parker and Dunn (1972) who envisaged that the spread of cable television would bring information directly into the homes of those who could afford the technology and exclude those who could not. In 1976 Parker reiterated concerns about the polarising societal impacts of the revolution in access to technologies and networks, i.e. information poverty and exclusion. Similarly in 1973, Martin was hypothesising that poor access to educational opportunities would lead to information poverty.

A LIS conceptualisation of information poverty or information inequality began to surface in the literature in the 1980s from both a research (Murdock and Golding, 1989) and a library practitioner perspective (Lang, 1986). Dervin (1998) focussed on Sense making, the goal of which is 'to find out what users - audiences, customers, patients, clients, patrons, employees - "really" think, feel, want, dream' (ibid, p. 19). While continuing to believe that information use is a manifestation of sense making on the part of the user, in 1994 Dervin questioned the simplistic assumptions or myths as she terms them which underpin the argument that information access can empower, concluding: 'in effect everyone is information poor, not just those who seem to lack access by current standards. In this framework, the very fabric of our information world would be built on premises too narrow for the richness, complexity, and elusiveness suggested by the alternative assumptions' (Dervin, 1994, p. 379) 
The concept of information poverty has also been considered in terms of governmental policy (see, for example, Meyer and Kraft, 2000), in an increasing move toward egovernment or technology-assisted interaction with government at all levels. From a communications perspective Norris (2001) concludes that information poverty is particularly corrosive in the context of discouraging citizen engagement and participation in the democratic process, echoing some of the prevailing myths noted by Dervin (1994) as outlined above. In her influential monograph, Norris (2001), deals with information poverty and the digital divide as a phenomenon of the late twentieth and early twenty first centuries, considering the power of new information and communications technologies as a way to encourage greater civic engagement: this remains a power however with the potential simultaneously to exclude and create new divides. Norris characterised the resultant divide as the gap between the information rich and the information poor which she argued exists in all countries.

Indeed, the political domain is a particularly fertile ground for research into information poverty, as a result of this sense that users without the ability to access and use information are at a disadvantage, as can be seen in, for example, Murdock and Golding (1989) who equate information poverty with political inequality. Similarly, Lievrouw and Farb (2003) recognised 'the growing attention being given to informational inequities in an increasingly information-driven global economy' (p. 499) and note that 'questions of informational equity must be reassessed periodically in light of changing social, political, cultural, and economic conditions' (p.500).

When viewed as a question of the digital divide, researchers tend to look at the problem from a more concrete base of how systems and technologies can create barriers to information for groups in society; for example Bertot,( 2003) sets out the variety of problems people might encounter in accessing information (see also, Jaeger and Thompson, 2003). The focus might be on political participation (Helbig, Gil-Garcia and Ferro, 2009) or on health (Wyatt et al., 2005), while much work focuses on the deficiencies in infrastructure in developing regions. There has been interest in the topic of information poverty from a computer science perspective (see, for example, Sweetland, 1993). Eastin and LaRose (2000) explored information poverty in terms of user capacity and confidence in interacting with internet enabled information. In terms more specifically of the concept of the digital divide, social scientists such as Warschauer (2004) have been interested in the extent to which social exclusion can be the outcome of lack of access to or expertise in using ICTs. Selwyn (2002) traced the evolution of the information age and conceptualisations of the digital divide as it became a prime focus for the social inclusion policy agenda of the 1980s and 1990s. Van Dijk \& Hacker (2003) set out a framework for understanding conceptualisations of the digital divide based on the kinds of access that were being considered by researchers and predicting a widening future user access gap. Terminologically the digital divide, rather than information poverty, has been the preferred term amongst computer science researchers and a full review of its treatment is outwith the scope of the present paper.

Mossberger, Tolbert and McNeal (2007) deal with the concept of the digital citizen: they both recognise the importance of information and technology access as means of encouraging political participation in decision making and policy formulation, while also recognising the extent to which citizens may face challenges in exploiting these rights and opportunities. In line with such constructs, European Commission policy has addressed 
information deficit as a challenge to the democratic process from a highly rationalist perspective and many other governments have followed suit. One of the present authors' work on 'citizenship information' has been built on a desire to explore further how information policy, systems and services can better serve citizens' information needs, in delivering both information to help them access opportunities or enhance their lives, as well as information that enables and encourages them to participate in democracy (see, for example, Marcella, Baxter and Moore, 2002).

While comparatively little research tackles the concept of information exclusion, Caidi and Allard $(2005$, p.1) argue that the focus now needs to move from generalised notions of information poverty towards building systems aimed at meeting the needs of specific groups, by providing the right kinds of information resources to meet their needs as codesigned systems that are nuanced to recognise cultural sensitivities and linguistic requirements. In line with this ethos, others have argued the importance of design predicated on acknowledgement of user needs: for example, Pateman (1999) argues that LIS should operate from a perspective of required inclusion and inclusive diversity in attempts to challenge information poverty, while Muddiman et al. (2000) stress the important role of public libraries in enabling social inclusion through access to information. Thompson et al. (2014, authors' abstract) take the exclusion theme forward in consideration of digital exclusion and the public library, examining 'the interrelationships between digital literacy, digital inclusion, and public policy, emphasizing the impacts of these policy decisions on the ability of individuals and communities to successfully participate in the information society'. Equally ICTs may have had a further complicating effect on the issue of information poverty through information overload, as Goulding (2001, p.111) concluded: 'instead of a dichotomy between information 'haves' and 'have nots', therefore, perhaps we need to think of access to information as existing on a continuum with three points: information poor, information rich and information burdened'.

Inevitably the topic has been of interest in terms of policy, sustainability, development and developing nations (see, for example, Heeks, 1999, Cecchini and Scott, 2003 and Kenny, 2002) and in a food poverty context (Torrero and Von Braun, 2006). Geographers (see, for example, Graham et al.,2014) have considered information poverty as manifest in user lack of capacity to generate information on the internet, in the information poor being therefore little heard and with the potential for their voices to be lost as part of our understanding of the world.

One of the most significant and substantive bodies of research has evolved around health information and poverty, in recognition of the role that information can play in enhancing health outcomes: such work has been carried out by health researchers and practitioners and by those working in LIS. Osiobe as early as 1989 set out health information imperatives for third world countries, noting that 'the legacy of the oral tradition in most Third World countries has impeded the recognition of the pivotal role of information in the everyday life of modern people.' The author argues that health professionals themselves must be better educated about the information resources that exist in a broad range of health contexts and that 'the near absence of health information has allowed quacks and quackery ... to flourish in the Third World' countries which have 'near to zero health information systems', (Osiobe, p.10-11). Pandita, Singh and Dash (2008, p.7) argued that in order to enable equitable access to quality health information in developing countries 'there is a need to bridge the digital divide between the haves and have-nots. Reliable connectivity and 
Internet access are foremost to ensure free and easy access to health information. Upgrading IT skills and training in effective searching of information come second followed by overcoming economic, cultural, and political barriers'.

Clift-Matthews (2010, p.160) emphasises the power of health education and the communication of information and knowledge to enhance Africa's future. She notes current challenges relating to 'how much information is reaching young people today about their sexual health' and that 'there is little known about the effectiveness of information dissemination among young people in African countries'. Reinforcing the real impact that might be achieved by reducing information poverty, Neter and Brainin (2012, p.1), in a survey of Israeli adult population, found that 'respondents who were highly eHealth literate gained more positive outcomes from the information search in terms of cognitive, instrumental (self-management of health care needs, health behaviors, and better use of health insurance), and interpersonal (interacting with their physician) gains.'

\subsection{Gaps in the literature}

Practitioner literature generally, as in many subjects, tends to focus more on mechanisms to overcome gaps in and barriers to information access from a constructivist perspective: while conversely much of the academic research reflects interpretively on the challenges for individuals/organisations. It is vital that discourse take place between academic and practitioner communities to uncover new knowledge to meet both agendas. Notions of extreme forms of information poverty and disadvantage merit much further study (Caidi and Allard, 2005), building knowledge of the phenomenon of information poverty amongst select groups of people, who have been denied access to the tools necessary for selfsufficiency (Mayer, 2003). Very early notions of groups of interests are hypothesised by the authors to be: people with severe learning difficulties; refugees and the displaced, whether economic migrants or refugees (see, for example, Lloyd et al., 2013, and Bronstein, 2017); people who have been victims of slavery or trafficking; people in isolated and remote places; and fourth age nursing home residents. The relevance of this research has not abated; indeed, it has become ever more pressing as the gap between the information rich and poor has arguably widened (see, for example, Chowdhury and Koya, 2017).

A related and currently highly topical phenomenon is that of organisations and people thinking themselves information rich, when they lack robust and trustworthy information, as manifest in recent political campaigns now leading to wider recognition of what is being termed 'post fact' (alternatively 'post truth') politics, where information poverty or deficit can be encountered by users not traditionally regarded as in poverty or disadvantaged. The notion of information deficit is one that has been largely ignored in LIS, although recognised as a challenge in behavioural psychology (see, for example, Zukin \& Snyder, 1984).

There remains an important and busy agenda for research into information poverty. We are at a time when there has never been more information, more readily available than there is now. And yet the benefits of enhanced access to information have yet to be realised. There are a variety of reasons why the challenge remains, such as public health messages that are unpalatable or culturally incoherent, where hierarchical social structures influence or damage information communications and flows, resulting in misinformation and miscommunications: this may or may not be intentional. A related phenomenon - that of 
the existence of cultural constraints on information access and use, alongside the continuing power of cultural myths and icons - might also form part of the debate. The continuing existence of extreme information poverty or deficit, despite wider and easier access to information technologies, also merits further exploration to determine the causal factors underpinning inequalities, in order to reduce poor information literacy amongst a variety of stakeholders in health, politics, education, economic sustainability and cultural and social interaction. There are significant challenges for information users in evaluating the quality and reliability of the information available, in separating fact from opinion in particular, in a world where knowledge is fundamentally complex and changing and poetically overwhelming in its scale.

These and other research questions emanating from this review of the literature informed the design of a focus group which sought to elicit the views of LIS academics on the current agenda for information poverty research, the results of which are presented in this paper.

\subsection{Research methodology}

This paper has three objectives:

i. To map key factors or contributors to information poverty;

ii. To gather views and opinions from a group of LIS academics about the current status and future potential for information poverty research.

iii. To begin to populate a framework for information and library research to contribute in an impactful manner to the societal challenge of information poverty.

The method used to gather data was that of a roundtable discussion or focus group which brought together a group of LIS subject experts to debate a set of questions set by the authors. The discussion was held at a conference, 13: Information; Interactions; and Impact in June 2017 and facilitated by the authors. The session was offered to all conference attendees in competition with three parallel sessions. The roundtable was entitled 'Empowerment through information: tackling barriers to information and information poverty amongst disadvantaged groups'. 11 individuals attended the session and they constituted a mix of academics and doctoral students from primarily UK institutions with two from non-UK institutions. Participants were interested in and had conducted research relevant to the topic of information poverty. It should be noted that these participants were not experts specifically in information poverty: their research interests covered a very much wider range of fields. They were, however, reflective of the wide range and constitution of research interest in LIS and, it should be noted, keen to participate voluntarily in the group discussion. Participant views are, therefore, reflective of general or wider interest amongst LIS academics in the topic of information poverty in 2017. It is fully acknowledged that this was a pragmatic approach to the generation of data (in line with Maxcy, 2003, and Feilzer, 2010), which exploited an opportunity to assemble a convenience sample. The research was, however, carefully designed, underpinned by the literature and the data collected were treated with the same care as might be expected from a more traditional project.

The discussion was designed as a classic focus group, a data collection tool that has long been considered useful in 'generating hypotheses, exploring opinions, attitudes, and 
attributes, testing new product ideas, evaluating commercials, and identifying and pretesting questionnaire items' (Fern, 1982, p.1). The research was exploratory in looking to surface participants' 'attitudes, priorities, language and framework of understanding' in relation to information poverty in the context of LIS research (Kitzinger, 1994, p. 116). Kitzinger (1994) emphasises in particular the value of focus groups in encouraging interaction amongst a group of research participants. Stewart and Shamdasani (2014) and Morgan (2013) argue the importance of careful moderation of focus groups in order to ensure the consistency and rigour of results. Typically the moderator will remain independent of the discussion that takes place: however, in the current research it was recognised that the moderator or facilitator was part of the group, , as evidenced by their previous research into areas related to the topic and their standing as an academic, and therefore, was an insider with contributions to make to the discussion. The moderator, therefore, took a relatively active role in engaging with the themes, while not leading the direction of group response. The moderator has previously undertaken focus group research in a range of contexts: exploring information behaviour in political decision making; and as a tool to elicit examples of information beliefs (see, for example, Marcella, 2018). It was made clear to participants at the outset of the discussion that it would take the form of a true roundtable with free-flowing discourse and ideas emerging, rather than as a presentation by the authors followed by questions and debate. The presentation slides posed questions rather than presenting results, and from the start the discussion was free flowing with only brief hesitations. Only after the group had exhausted consideration of a question did the two authors make observations. It was helpful in encouraging discussion by all members of the group that the moderator knew most of the participants and was broadly familiar with their areas of research expertise.

Significant themes emerging from the literature were used to create a set of open questions to be presented to participants: these are set out below:

1. How would you construe information poverty?

2. What aspects of poverty most concern you?

3. How is poverty different in the $21^{\text {st }}$ century? UK/worldwide?

4. Which are the most important areas of academic research in tackling poverty today?

5. Which interventions do you believe to be most important/essential in tackling poverty - e.g. education, health, contributing to relief?

6. How important is information poverty today as a field for focus in information science research?

7. What aspects of your own research or of that of others known to you in LIS is relevant to this debate?

8. What/How can we, in IS, best contribute to the problem of solving poverty?

9. Which research questions should be high priority for us?

10. Which other disciplines should we seek to work closely with to extend knowledge?

11. Does technology help or create another barrier to information for those living in poverty?

12. What forms might poverty take in an information rich world?

13. Are there particular themes/groups worthy of further exploration?

14. Are new examples of disadvantage emerging? 
The session lasted for 90 minutes and was structured around a Powerpoint presentation consisting of the questions listed above, with supporting imagery, in the form of visuals sourced via a Google image search by relevant phrases. Slides proceeded in a structured manner, from historical and current images of poverty and disadvantage through definitions of information poverty (Chatman, 1996 and Dervin, 1980) to related concepts drawn from infographics produced by the UN, the Joseph Rowntree Foundation and the Melissa and Bill Gates Foundation. Illustrations relating to, for example, the digital divide, protected characteristics, and initiatives to empower specific groups were also shown to encourage relatively free-form debate. The movement of the discussion was designed to lead from definitions of information poverty, through manifestations of poverty today, reminders of the ways in which people encounter poverty, distinctions between information and digital poverty, the concept of the information divide, the sense in which information poverty is a right and proper concern for academics and practitioners in LIS, and the priorities for future intervention whether research or practice-led. They were asked in the order indicated in the list above.

Discussion was lively and wide ranging with all members of the group offering insights and reflections. It was recorded and transcribed (10500 words), and subsequently coded into broad themes, which were then used to organise the results in the findings section (4.0) below. These themes are:

- definitions of poverty and information poverty;

- literacy and information literacy;

- information to reduce poverty - government information;

- LIS initiatives tackling information poverty; and

- social justice and information.

\subsection{Results}

The discussion which took place on information poverty was wide ranging and somewhat chaotic at times. However a number of significant themes emerged and were given extended consideration by the group. Inevitably these reflect the particular interest of this particular group of 11 academics and they are by no means regarded as exhaustive or universal. However they do indicate what were seen to be important areas for LIS to focus on in terms of information poverty and how and where it was thought future research would have value and impact.

\subsection{Definitions of poverty and information poverty}

Three key forms of information poverty were identified: (i) the lack of information, misinformation or disinformation; (ii) the lack of capacity to use information and data to make sound decisions; and (iii) the lack of capacity to create information and participate in informing society.

Participants began by debating how people might be information poor but not actually financially destitute, indeed might be affluent, yet not have the skills needed to gather the 
right information. The point was made that information can help to tackle all aspects of poverty, whether with regard to climate change or for the eradication of hunger and poverty. Yet despite the fact that such information and data exist, they may not necessarily meet people's information needs. Broadly, it was acknowledged that information poverty remains a major issue both in Low and Middle Income Countries (OECD, 2017) as well as in apparently wealthy societies, where extreme disadvantage exists side by side with privilege.

Another theme related to demonstrating the capacity of information to empower individuals to overcome barriers and challenges associated with poverty. It was felt to be important to show or evidence compellingly how we as a discipline can empower people however disadvantaged - in any aspect of their lives, through access, use and sharing of information, whether for health, education, political decision making, in business and so on. The importance of LIS working with researchers and practitioners in other disciplines and professional domains, such as health, was emphasised throughout the discussion if we were to demonstrate impact and achieve real progress in eradicating information poverty.

In talking about information poverty one participant cited BREXIT, when in 2016 the U.K. electorate voted in a referendum to leave the European Union, as an example of a situation where people had taken a decision based on inadequate information. After the referendum many voters admitted quite openly and proudly that they'd made a decision based on either being information poor - not having the facts - or having inaccurate and inappropriate facts and not being able to sort out the wheat from the chaff. The participant felt the results had been catastrophic, a view based not wholly on their political views but as illustrative of the course of history being changed as a result of information poverty. The vote was cited as an example of the lack of capacity of individuals to access reliable information on a national scale: this reinforces Lievrouw and Farb's (2003) argument that it is necessary that questions of informational equity be periodically reassessed in a rapidly changing world. Participants noted the importance of developing users' capacity to make informed judgments and to understand that in a complex world there might be alternative facts and ideas that are contested, views that will never be reconciled but still a need to make the best-informed choice possible, in line with Dervin's (1994) view of the complexity and elusiveness of the reality of our information world.

Information poverty was felt by some to be endemic today, due to the complacency of people who think that the ability to use Google or Wikipedia equates with information literacy: that many see the mere location of information that meets their purpose as a validation and demonstration of their information literacy. Society and educational institutions do not typically teach people how to use information in their everyday life problems and how to make decisions based on that information. Yet such information skills are fundamental to education, research and decision making.

For the discipline as a profession, two important production activities were specified: (i) the creation of the tools to access the data and information: and (ii) responsibilities around ensuring that there are ways of guiding users to sources of data and information that are accurate and reliable. LIS research focuses often on how people and society use information and much more needs to be done by LIS on how we construct tools to access information: much of this activity has been taken over by the computer scientists and technologists, LIS may need to re-examine its role in providing, accessing, monitoring and evaluating the 
quality of information, securely underpinned by our understanding of how that information will be used and in recognition of the fact that information poverty has not been eradicated by the information systems that users have access to today. Better systems to support those who have challenges in accessing information for whatever reason need to be developed, suggesting that Warschauer's (2004) concerns around user lack of technological expertise continues to lead to social exclusion.

Participants discussed the way in which LIS has embraced the move from keyword towards natural language retrieval, with less apparent work on controlling language. The concepts of classification and metadata were felt to have got somewhat lost yet the infosphere still needs those basic principles of how you curate the ill-regulated mass of information to make it accessible in the right way for the right people. Events over the recent past reinforce a heightened awareness of the need for information to be regulated by disinterested experts (see Zukon and Snyder, 1984 and Baxter and Marcella, 2017). Inevitably a link was drawn by participants to 'fake news' here. We have as a discipline surrendered the responsibility for information quality to information technology, to develop in whatever way computer scientists felt appropriate and there was no real recognition of the critical need for LIS to engage with IT about how to do so most rigorously. There was a recognition of the need to continually reappraise technological advances in terms of their potential to exacerbate Lievrouw and Farb's (2003) informational inequities.

From a systems design perspective it was argued that for those designing information systems the base assumption had always been that a high-quality system should require no guidance for users: it should be intuitive. However worthy as this aspiration might be, it means that the user step of understanding how the system works and of what it consists is inevitably missing. The visible signifiers of authority, evidential base, and so on are all missing by design. The focus of the system designer is very much on creating invisible automated mechanisms (see, for example, Bertot, 2003) to cater for user learning deficiencies but this may have ultimately proven counterproductive as the human reliance on machine in interrogating information means that intelligence in search is becoming very remote and largely (apparently) unnecessary. To an extent, computer scientists believe they can create systems that obviate the need for human intelligence in processing information: library and information science is more interested in building human intelligence to manipulate systems wisely and well and might do so by mediating collaborative partnership with users and computer scientists in line with Caidi and Allard (2015).

\subsection{Literacy and information literacy}

At its most basic level simple literacy remains a real issue for many and for many living in poverty. We have moved away from a world where knowledge was curated in buildings where you had to demonstrate your capacity to enter that building, in which you are permitted to access knowledge and information, to one where it's there (apparently) for everyone but yet it is potentially being abused and misused to a greater extent than ever before. This was felt to be a part of information poverty in the twenty-first century.

Visual information and 'easy read' versions of manifestos and documents were produced for a time by, for example, the U.K. Government, and although these were largely aimed at people with learning difficulties, the wider public appreciated those as well. The Plain 
English movement was also a recognition of the need to communicate information with greater clarity. And, of course, for LIS researchers, the consideration of the prevalence of low levels of information literacy was a recurrent theme in the discourse: as Behrens (1994, p.316) notes 'in an information society, information literacy could be seen as an extension of the literacy realm'. It was noted that users often had an expectation that information exists which doesn't: for example that there must be a simple, unequivocal and uncontested answer to their health related question or that it should be possible to access a simple guide to what BREXIT would mean. And so, efforts to overcome information poverty must consider how best to convey an understanding of the complexity of the world and the nature of factual information. When thinking about open data and linked data and when a user is seeking to compare different arguments around an issue, perhaps from differing disciplinary or professional perspectives, there may be a mistaken assumption that if data are not found then they do not exist. One participant commented that users are frequently 'checking their brains at the door when it comes to working with these datasets because there are assumptions that it [i.e. the sought information] is there'. Levy's (2007) critique of the focus on speed and quantity of information access and use was felt highly relevant. Big data has led to complacency and to the belief that if information is important then it will be found, it will emerge. The concept of memory was also felt to be relevant to the debate and the capacity to recall information when needed - whether by human or system agency.

One participant spoke of an early career experience when employers had instructed that information be made less visible to service users, despite their legislative right to access and use that information, in line with research into non-issues whereby policy areas are obfuscated to deliberately reduce debate. Despite increased emphasis on government consultation in policy making, it was felt that these were becoming what has been termed nonsultations (see, for example, Gilligan, 2010), where 'the purpose of "nonsultation", however, is almost never to act on the public's views. It is to manage, manipulate, or suppress them'.

Poor citing of the sources of information was also felt to be a major challenge for users in terms of their capacity to judge information quality, as in the simple noting of ONS (Office for National Statistics, U.K.) at the bottom of a post, which is relatively meaningless for most users and impossible to follow to the actual source of the data.

In the context of current debates around 'fake news' and 'alternative facts' and the pervasive but subtle influence of 'the echo chamber' of the Internet as argued by, for example, Arvidsson (2014), it was noted that new forms of information deficit were being revealed, in phenomena such as the reliance users place on varying information sources, over-reliance on narrow funnels of information on social media, and challenges in accessing information in ways that are simple, clear and unambiguous. Social media's short bursts of information satisfy a need for concise and readily understandable and digestible information but may fail to reveal the rich complexity of debate and contention around an issue. This is a concept that would have been summed up in what we in LIS would have called information consolidation (Saracevic, 1986). 


\subsection{Information to reduce poverty: government information}

In order to alleviate poverty, the most obvious source of information for the individual faced with poverty is government, be it local, national or devolved (in line with, for example, Meyer and Kraft, 2000): yet despite the billions of pounds that have been invested by government in information systems over the last twenty years many of these have failed miserably and this was thought to be related both to poor digital literacy and to the fact that there is minimal evidence of user testing being undertaken as part of systems design (c.f. Selwyn, 2002). Little thought has been given to the needs of eventual users, who are the hypothetical beneficiaries, on, for example, welfare benefits or legal rights. Government information resources are often impenetrable: if that information was presented in a more visual way it might reach out to many more people (Pickard, 1998).

The UK government's 'digital by default' policy has moved information provision online (Selwyn, 2002) and much work has had to be undertaken to support the many people who are finding these new systems difficult to use (see, for example Yates, Kirby and Lockley, 2015). Initiatives have been put in place by, for example, Newcastle City Council, to create digital leaders or champions, to train people on benefits, the elderly, those on pensions, who have never used any IT systems, who are now told their entire life is accessible through that system and only through that system because there's nobody there to help them. Information poverty for these people is real and affects aspects of their daily lives. The level to which that then disenfranchises many people was felt to be reinforcing rather than reducing the information divide, in line with Meyer and Kraft (2000) and Mossberger, Tolbert and McNeal (2007).

Equally it was thought that the 'one size fits all' approach of systems design was failing to recognise the specificity of information need in line with Caidi and Allard (2005) - again a concept very familiar to those of us working in information retrieval 20-30 years ago, that in order to be useful, information needs to meet a user's requirements in terms of subject, level, timeliness, language and so on. Rather than giving the user more control over what they find and greater opportunities to frame a precise and specific information need, search interfaces are often designed based on all sorts of ill-understood algorithms with little recognition of what information is needed, by whom and why. Recent research (see, for example, the Lyon Declaration, in Statista, 2018) is focusing on understanding better for what purposes the public are using the Internet from home and mobile devices, (e.g. online banking and shopping etc.) and on exploring with what level of ease or difficulty different demographics engage with systems and whether such resources are being used optimally. Help and support on many systems are particularly poor and this again leads inevitably to information poverty for those without strategies to work their way through complex systems.

The group generally concurred with a view that e-government has shifted the responsibilities for e-admininstration to the user (from participants' own research into user interaction with government information sources) and that at times barriers appear arguably intentionally, with the intent to hinder and constrain, for example, utilisation of Freedom of Information rights or to stop people accessing information deemed undesirable. Governments were not necessarily benign entities working to make information as 
accessible as it should be and information poverty may be the desired (if unstated) official outcome as part of a process of obstruction or obfuscation. Given recent revelations of the impact of the release or non-release of data about FBI investigations on the 2016 U.S. Presidential election, this is a challenge that will become an ever greater concern for societies in the future: Gore (2017) provides a useful overview of information abuse in politics.

The group believed that Chatman's (1996) notion of the impoverished life space of the information poor, which might be in a mansion or a refugee camp, remained relevant today. Chatman talked about secrecy, deception, misinformation and the idea of small worlds: these concepts are valuable to us today, for despite greater access to a global information superhighway (as we used to call it) an individual's world can be a very small one. The capacity to link the world has created huge opportunity while in some respects resulting in greater isolation of people in a small world, an information bubble, an echo chamber (see Colleoni, Rozza and Arvidsson, 2014).

And so the group asked themselves 'has technology helped?' While in the majority of lives, access to information has been enabled to an extraordinary degree over the last thirty years, the chasm between the haves and the have nots seemed to grow ever deeper as a result of technology. Equally, the ways in which people can be information poor have arguably proliferated. In 2017, BT research (Yates, 2017) into limited and non-users of internet technologies reveals a very significant mass of people in the U.K who are not engaging currently and may never engage with digital technologies for reasons of poverty, education, etc. The UK digital heat map (Yates , 2017) indicates where digital access is high and low, indicating a partial rural/urban divide, alongside inner-city areas of deficit. It also indicates a major challenge for vast swathes of England, Scotland, Northern Ireland and Wales. There are various associated programmes such as Go On UK, part of the government's digital inclusion programme, which are designed to encourage citizens in making the move online. The issue was felt to be less about the access and more about information quality: however, the divide remains concerning for those in less well served regions.

\subsection{LIS initiatives tackling information poverty}

Information poverty is most critically manifest in developing countries (LMICs), often with an emphasis on empowering people through good health. In the most significant LIS initiative, IFLA has sought to align public libraries in LMIC countries as part of an international advocacy programme, the Global Libraries Initiative, supported by the Bill and Melissa Gates Foundation. The Global Libraries programme was set up specifically to try to address the information divide, by finding ways of providing wider free access to the internet to people who either didn't have any access, or who only had very limited access at a cost beyond their means. The program was realistic in its aspirations, not intervening in the places with greatest poverty, but in countries with sufficient information infrastructure and a network of public libraries upon which to build (Sawaya et al., 2011). The programme is due to complete in 2018, with 3 legacy partners, the Public Library Association, the 
Technology and Social Change Group at the University of Washington (TASCHA) and IFLA, to continue the work through the International Advocacy programme.

The Lyon Declaration on Access to Information and Development (2014) is also significant in this context. It is an advocacy document drawn up by multiple signatories, including IFLA and a number of strategic partners in the library and development communities, to positively influence the content of the United Nations post-2015 development agenda, by highlighting the significance of access to information in enabling economic and societal development.

In an associated piece of work, the International Development Research Centre looked at mobile technologies and their capacity for bridging the information gap. It was assumed by many that information poverty would end as a result of wider access to information through technology: however, there is still much work to be done to ensure that meaningful access to information be within the grasp of many in developing regions. Research in India had provided some evidence that mobile technologies can empower women (Tenhunen, 2008). In a similar vein, work done in Citizens' Advice Bureaux (Beer, Marcella and Baxter, 1998) saw mobile technology as playing a role in overcoming user anxiety at being observed entering a place associated with need. While acknowledging the potential of technology to assist, the point was made that training and support remained critical for those in greatest disadvantage. It was thought that LIS should do more to work with international development researchers and to engage in particular with the Global Libraries legacy partners to ensure that work continues and is fed by research and in turn inspires early career researchers and practitioners to carry on this area of potentially high impact intervention and to reinforce the comments made by Scheeder (2018) of the continuing critical role of libraries in comparting global information poverty.

\subsection{Social justice and information}

In data science, research is ongoing into issues of data literacy and the capacity of communities who are particularly disadvantaged (see, for example, Jaeger, Bertot and Thompson, 2012), who are left out of data as evidence and who are therefore excluded from representation and don't have the capacity to counter or challenge the data and discourse, which are essentially politically fuelled. And so information poverty also has resonance for those whose voices are not heard and who do not have opportunities to create information about our world. The voices of the information poor thus lose the transformative capacity to become used as information and to be acted upon in line with the findings of Graham et al. (2014). There is a continuing opportunity for greater coproduction and co-creation with marginalised or silent groups (see, for example, Cloke, Cloke, and Little, eds., 1997).

It was argued that counter forces come into play such as the hegemonic forces that are better at producing and proliferating information: natural language tagging relies on the data out there, and what bubbles to the top is what's written about the most, and so it has a way of becoming a self-fulfilling prophecy. The information poor will inevitably become the not-represented or under-represented or misrepresented. So developing a capacity amongst all users to produce their own data and information becomes the critical starting point before they can start accessing it. This was vital going forward as a way of rebalancing 
society's picture of itself, particularly in a world where big data predominates. The concept of information enablement predicted that the internet would open up the capacity of people to say things but in a world where there are so many voices, saying so much, users struggle to make their voices heard in a meaningful way.

Power was felt still to lie with the people who own or hold the information. One example is healthcare, where it would be useful to consider how people who hold the power empower others and to what extent the holders of power have an obligation to pass on that knowledge to others. LIS academics and researchers should work with others who are the guardians of information in their fields to share our understanding of information behaviour and need with them. It will be in working with other disciplines that the most effective interventions and mechanism to overcome information poverty will be uncovered.

Brenda Dervin's work in Baltimore in the 1970s (Dervin, 1980) was a reminder to the group that the perennial human questions do not disappear, they rather persist, albeit in a new guise. Ethical questions around digital information and its use and abuse were becoming prevalent, as argued by Britz (2004): a theme which has become ever more persistent since the group discussion took place.

A call was made for research into the extent to which many of the world's critical events can be traced back somewhere to an absence of capacity to engage with data or information. Many examples were cited from the fatal Grenfell Tower fire in London, through the Deepwater Horizon disaster in the Gulf of Mexico and the Piper Alpha incident in the North Sea. In all examples critical information failures had occurred. Research might usefully mine post hoc incident investigations to determine where knowledge, data and information had failed. Often multiple critical information failures characterise these events in a manner acknowledged by the Swiss Cheese Model in health and safety research (Reason, 2000).

In the case of the catastrophic Grenfell Tower fire, which resulted in numerous fatalities, there were multiple sources of information, for example manufacturers' directions for how to use cladding, that were not known of or not used. Accountancies are relevant in this context too - who should have seen and signed off the information, at what point was human intelligence involved and was that sufficient? In certain instances, information would have been less available to a disadvantaged group of tenants than to wealthy information-rich owner occupiers. Equally, residents might have been information rich yet their financial poverty would have paralysed them in terms of their voices being heard, of knowing how to use that information. There was also felt to be a question about organisations and governance and rational entities who seem able to abnegate responsibilities despite - or even because of - sophisticated information systems

Particular note was made of the protected characteristics and equalities which suggest a further prism through which to think about social exclusion (see Citizens Advice, 2018). Research might usefully explore the particular information needs of groups in extreme disadvantage or where there is a duty to provide support. Research forays into many of these have already been made from an information science perspective and some means of mapping thinking drawn from all of these was felt to be desirable. One area of notable contribution was around refugees, increasing number of migrants, economic, political, societal refugees and the issues that they face locating information to help them out of poverty (see, for example, Lloyd et al., 2013 and Bronstein, 2017). Recent campaigns tackling domestic abuse might provide a useful fulcrum for research in this context. Equally 
historic abuse enquiries are revealing the extent to which important information has not been preserved by responsible authorities. The link to the idea of a civic society and people's civic responsibility to their community was made by one participant, who hypothesised that individuals' civic responsibilities are morphing in a new world of greater access to information about ever wider groups of people and the extent to which all users are becoming providers as well as users of information.

Social media was also cited as a world in which such civic responsibilities were being tested in new ways, where for example a communication 'crosses a line' and others in the group feel obliged to report what people are writing. There is a sense in which lives can be changed because of making information public that might not ever previously have been stated openly. Information sharing has almost without voluntary cognition become less covert and more visible. Equally, it is much easier to be exposed to information that you didn't want to see. Reference and information provision used to be regarded as a safe place to ask questions, but many of the information and support networks that are now increasingly available online are far from being safe places. Research was recommended into how disadvantaged groups use advice and support networks online and whether such online sources help overcome issues around safe and anonymous spaces, where to date much of this space has been occupied by health support research (see, for example, Cotton and Gupta, 2004). A particularly desirable area for exploration was felt to be youth suicide and youth depression, where there is evidence of both positive and negative impacts of online information sources and there remains a proliferating problem (Szumilas and Kutcher, 2009). Teen suicide information on the.

\subsection{I n summary}

This was a very wide ranging and lively discussion covering a wide variety of aspects of information poverty and it illustrates that there are many aspects of information poverty that would merit further exploration. Inevitably all that could we achieved in a 90 minutes discussion was headline level discussion, picking out some of these issues and that is what these findings have sought to present. For each and every one of these there is potential for further in-depth debate. However what can be drawn from the discussion is that there exists a wealth of presently significant research questions in terms of: how we should understand information poverty and how it might be construed by non-LIS researchers; the continuing importance of enhancing people's capacity to interact with information and information systems in order to overcome information poverty; how users interact with and are affected by government information initiatives, policies and systems; how LIS has sought to overcome information poverty and what contribution we can and should make as a discipline; and the importance of information in enabling people to achieve social justice. 


\subsection{Conclusions and recommendations}

The group concluded that there was a major piece of work to be done in reframing the LIS disciplinary approach to information poverty, in particular to bring together different strands of work in relation to specific disadvantaged groups. Group discussion participants agreed that LIS disciplinary engagement with information poverty is timely and relevant to society today. In the conclusions that follow the authors have drawn inferences and sought to bring together the most significant aspects of the discussion that took place, setting out an early iteration of an exploratory research framework for information poverty. Inevitably this paper can only set the scene for further research to take place and the authors hope to have regenerated interest in and appetite for research in this important field.

It was agreed that as a research group our primary motivation centred on social justice, education and socio-economic development in the context of information poverty, in line with Britz (2008, p.1181) where he argues that justice, if interpreted and applied in the correct manner, can be used as a universal norm to guide ethical decision making in the global Information Society'. We have a moral imperative to persuade other disciplines to act as advocates for information literacy.

Inevitably, from a smallish group of individuals, the topics surfaced in the discussion were by no means comprehensive, but they help to begin to sketch out and populate a framework of LIS research into information poverty. The group identified the four key dimensions of information poverty that merited collaborative future research: (i) information as an agent to eradicate poverty; (ii) the causal factors resulting in information poverty; (iii) creation and production activities to combat information poverty; and (iv) better understanding of areas of extreme disadvantage and aspects of information need. These topics are reformulated below.

(i) Information as an empowering agent Information remains a key agent for the eradication of poverty and other social evils, whether through enabling access to information as a means of overcoming disadvantage or enabling users to provide information to shape societal discourse. Research into information as an empowering agent would be valuable looking at: making decisions or lifestyle choices; having a voice; accessing and exploiting opportunities. This potential to empower should be further explored by analysing the different causes of poverty from lack or resources - money, food, health, clean water, sanitation, housing, education, etc.; and mapping how information and data management, access, sharing and appropriate use, can help us to tackle the causes of poverty and achieve sustainable development and address the U.N.'s Sustainable Development Goals (SDGs) and corresponding targets.

(ii) Causal factors of information poverty A variety of causal factors resulting in Information poverty have been identified and are set out below: 
a. Human and behavioural factors, such as the lack of literacy and lack of skills (even amongst literate people) to access, evaluate and use information; physical and cognitive disabilities, complacency; linguistic capacity.

b. Social and cultural factors such as lack of social structure or norms causing barriers to information access; epistemologies, faith, value and belief systems; social unrest, displacements/migration, etc..

c. Trust factors relating to politics and propaganda with the public sphere as a highly contested arena and increasing scepticism and lack of public trust, as exemplified in the UK Referendum leading to exit from the E.U., the 2016 US Presidential campaign, terrorist and anti-terrorist activities; the destruction of cultural heritage by extremist groups; and the growing need for fact checking agencies.

d. Information creation, distribution and management practices: organization and access to information; information overload; information quality; cost of information including cost of information per se, as well as the cost associated with its collection, processing, management and dissemination.

e. ICT, infrastructure \& systems including web, social media and mobile technologies, as well as the newly emerging persuasive technologies to alter people's information behaviour and/or beliefs.

f. National and international information regulations and policies or the lack of such regulatory regimes: including aspects such as secrecy around government information in some - indeed arguably to a greater or lesser extent in all - countries; obfuscation, misinformation and secrecy; banned or restricted access to information in certain countries like North Korea; privacy, ethics and sensitivity (e.g. around some indigenous information like the Maori culture in New Zealand).

g. Economic factors as in having the resources and capacity to create, manage and make information accessible.

h. Perpetual environmental disasters and calamities, such as earthquakes, floods, fire, famine, disease etc., causing destruction of information or the means to access it.

The key contributors to information poverty as elicited from the discussion are indicated in Fig.1 below: 


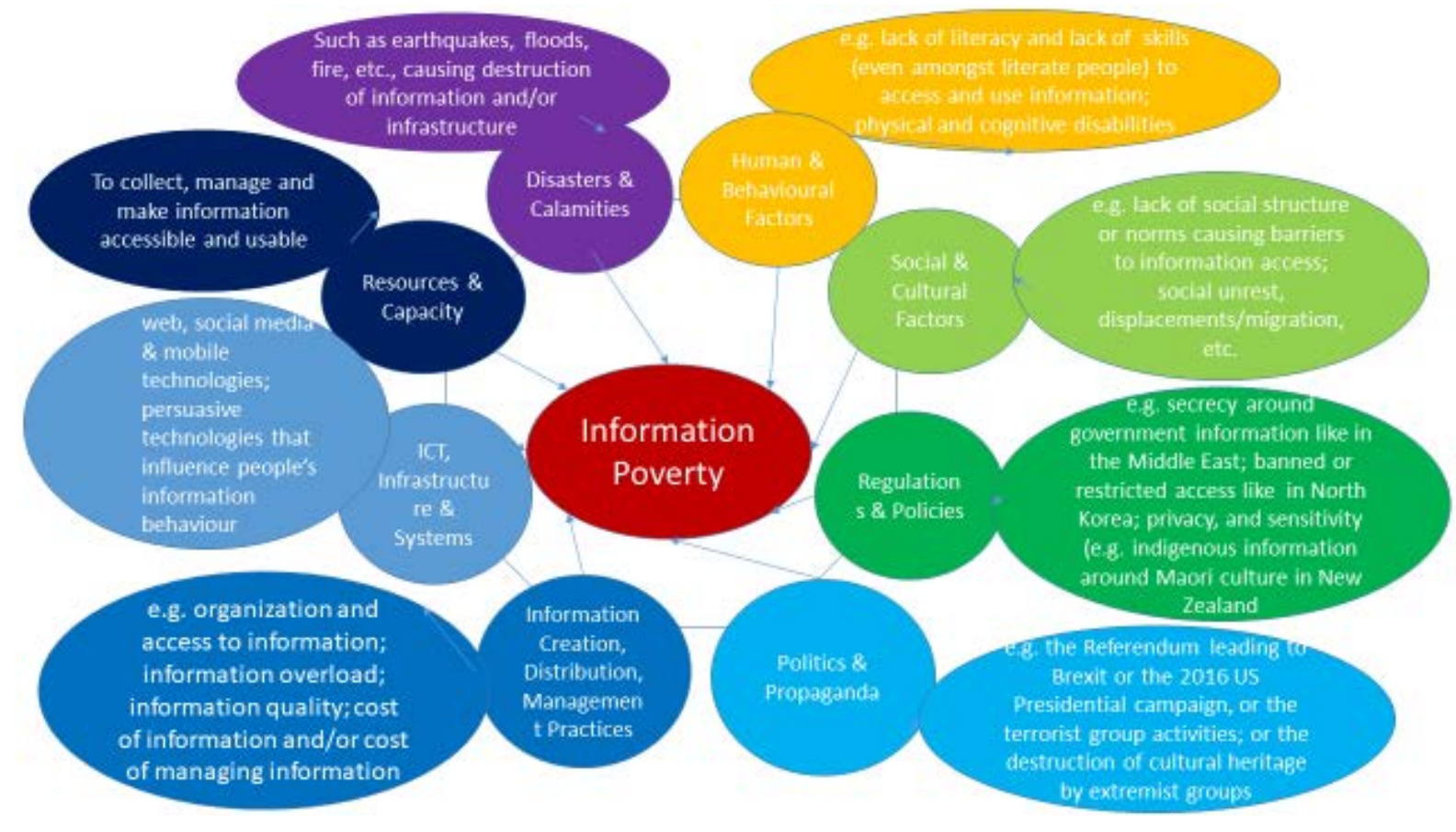

Fig.1: Key contributors to information poverty 
(iii) Information Production Activities It was considered critical that there should be continuing LIS input into the creation and production of resources and the delivery of services to combat information poverty, in recognition of the focus the discipline has always had on the user at the centre of information. These efforts might centre on mechanisms to curate the ill-regulated mass of information to make it useful to the right people at the right time and in the right way. Three production activities were identified: (i) creation of tools to enable access to information; (ii) guiding users to accurate, relevant, current and reliable information that meets their needs; and (iii) enabling disadvantaged groups to participate in information creation. This strand would build better understanding of the effectiveness of interventions with a concomitant focus on impact on individuals' lives. It was agreed that while computer science will continue to create new, more sophisticated and less comprehensible systems that obviate the need for human intelligence in processing information, for library and information science our focus should continue to be more on how we build human intelligence to manipulate systems wisely and well, fully acknowledging the barriers that exist for individual humans in doing so.

(iv) Enhancing knowledge of extreme information poverty LIS research should continue to build better understanding of areas of extreme information poverty or disadvantage and impact on information need. Perhaps counter-intuitively this might be helpfully achieved by considering the life experience of the information rich alongside that of the information poor to make concrete the actuality of the impact of that gap. Certainly it is the case that the concept of the information rich is changing and less concrete, obvious or visible signifiers of information poverty could fruitfully be explored.

\subsection{Research limitations}

It should be noted that this paper is based not on an extensive research project but on the pragmatic exploitation of the opportunity presented by a conference roundtable to gather ideas and opinions from a group of LIS academics and researchers on information poverty. The results can therefore best be regarded as exploratory with some potential to encourage future research. The authors regard the subject of information poverty as a vital one with which LIS research should engage and where we as a discipline need to set out our stall. The opinions, beliefs and priorities expressed by the study participants are indicative of where the LIS contribution to information poverty might best be made.

The framework proposed in this paper does not suggest that all of these topics should be subsumed under information poverty: it reflects rather that are all relevant to a consideration of information poverty and either influential in increasing information poverty or might help to alleviate it. The authors do not believe that there is a hierarchy of topics where information poverty sits as greater than and therefore subsuming information ethics or social responsibility of LIS, we regard them as interwoven and inter-connected, a fact which may make a consideration of one impossible without consideration of the others. Social justice is an aspiration, information poverty is a phenomenon which exists and information ethics might help us to understand why information matters if we are to achieve social justice for all. 


\section{References cited}

Adler, M. And Ziglio, E. (1996) Gazing into the oracle: the Delphi method and its application to social policy and public health. Jessica Kingsley Publishers.

African Health Observatory. Analytical summary - Gender and women's health. Available at: http://www.aho.afro.who.int/profiles information/index.php/Malawi:Analytical summary - Gender and women\%27s health\#cite note-three-0

Baxter, G., \& Marcella, R. (2017). Voters' online information behaviour and response to campaign content during the Scottish referendum on independence. International Journal of Information Management, 37(6), 539-546.

Beer, S. F., Marcella, R., \& Baxter, G. (1998). Rural citizens' information needs: a survey undertaken on behalf of the Shetland Islands Citizens Advice Bureau. Journal of librarianship and information science, 30(4), 223-240.

Behrens, S. J. (1994). A conceptual analysis and historical overview of information literacy. Available at:

https://www.ideals.illinois.edu/bitstream/handle/2142/41773/crl 5504309 opt.pdf?s

Accessed: 27/04/18

Bertot, J. C. 2003. The multiple dimensions of the digital divide: more than the technology 'haves' and 'have nots'. Government Information Quarterly, 20(2), 185-191.

Britz, J. J. (2004). To know or not to know: a moral reflection on information poverty. Journal of information science, 30(3), 192-204.

Britz, J. J. (2008). Making the global information society good: A social justice perspective on the ethical dimensions of the global information society. Journal of the Association for Information Science and Technology, 59(7), 1171-1183.

Bronstein, J. (2017). Information grounds as a vehicle for social inclusion of domestic migrant workers in Israel. Journal of Documentation, 73(5), 934-952.

Cecchini, S., \& Scott, C. (2003). Can information and communications technology applications contribute to poverty reduction? Lessons from rural India. Information Technology for Development, 10(2), 73-84.

Caidi, N., \& Allard, D. (2005). Social inclusion of newcomers to Canada: An information problem? Library \& Information Science Research, 27(3), 302-324.

Chatman, E. A. (1996). The impoverished life-world of outsiders. Journal of the American Society for Information Science, (1986-1998), 47(3), 193.

Childers, T., \& Post, J. A. (1975). The information-poor in America. Scarecrow Press.

Citizens Advice. The Equalities Act 2010. Available at:

https://www.citizensadvice.org.uk/law-and-courts/discrimination/aboutdiscrimination/equality-act-2010-discrimination-and-your-rights/ Accessed: 26/04/18 
Clift-Matthews, V. (2010). Protecting Africa's future through health education. African Journal of Midwifery and Women's Health, 4(4), 160-160.

Cloke, P., Cloke, P. J., \& Little, J. (Eds.). (1997). Contested countryside cultures: Otherness, marginalisation, and rurality. Psychology Press.

Colleoni, E., Rozza, A., \& Arvidsson, A. (2014). Echo chamber or public sphere? Predicting political orientation and measuring political homophily in Twitter using big data. Journal of Communication, 64(2), 317-332.

Cotten, S. R., \& Gupta, S. S. (2004). Characteristics of online and offline health information seekers and factors that discriminate between them. Social Science \& Medicine, 59(9), 17951806.

Dalkey, N., \& Helmer, O. (1963). An experimental application of the Delphi method to the use of experts. Management science, 9(3), 458-467.

Dervin, B. (1994). Information $\leftrightarrow$ democracy: an examination of underlying assumptions. Journal of the American Society for Information Science, 45(6), 369-385.

Dervin, B. (1998). Sense-making theory and practice: an overview of user interests in knowledge seeking and use. Journal of Knowledge Management, 2(2), 36-46.

Dervin, B. (1980). Communication gaps and inequities: moving toward a reconceptualization. Progress in communication sciences, 2, 73-112.

Eastin, M. S., \& LaRose, R. (2000). Internet self-efficacy and the psychology of the digital divide. Journal of Computer-Mediated Communication, 6(1), 0-0.

Feilzer, M. Y. (2010). Doing mixed methods research pragmatically: Implications for the rediscovery of pragmatism as a research paradigm. Journal of Mixed Methods Research, $4(1), 6-16$.

Fern, E. F. (1982). The use of focus groups for idea generation: the effects of group size, acquaintanceship, and moderator on response quantity and quality. Journal of marketing Research, 1-13.

Get Digital. (2017). Exploring exclusion from a digital United Kingdom. Available at: http://heatmap.thetechpartnership.com/ Accessed: 28/04/18

Gilligan, A. (2010) A Government ruse that's nothing short of an insultation. Telegraph, $20^{\text {th }}$ Aug. Available at: https://www.telegraph.co.uk/news/politics/7955561/A-Governmentruse-thats-nothing-short-of-an-insultation.html

Goulding, A. (2001) Information poverty. Journal of Librarianship \& Information Science, September 2001, 33 (3), 109-111.

Graham, M., Hogan, B., Straumann, R. K., \& Medhat, A. (2014). Uneven geographies of usergenerated information: patterns of increasing informational poverty. Annals of the Association of American Geographers, 104(4), 746-764. 
Haider, J., \& Bawden, D. (2007). Conceptions of "information poverty" in LIS: a discourse analysis. Journal of Documentation, 63(4), 534-557.

Heeks, R. (1999). Information and communication technologies, poverty and development. Manchester, UK: Institute for Development Policy and Management, University of Manchester.

Helbig, N., Gil-García, J. R., \& Ferro, E. (2009). Understanding the complexity of electronic government: Implications from the digital divide literature. Government Information Quarterly, 26(1), 89-97.

Jacobs, D. (2015) Impact planning and assessment of the Global Libraries initiative of the Bill \& Melinda Gates Foundation, Performance Measurement and Metrics, Vol. 16 Issue: 2,

Jaeger, P. T., \& Thompson, K. M. (2003). E-government around the world: Lessons, challenges, and future directions. Government information quarterly, 20(4), 389-394.

Jaeger, P. T., Bertot, J. C., Thompson, K. M., Katz, S. M., \& DeCoster, E. J. (2012). The intersection of public policy and public access: Digital divides, digital literacy, digital inclusion, and public libraries. Public Library Quarterly, 31(1), 1-20.

Joseph Rowntree Foundation (2018) What is poverty? Available at: https://www.jrf.org.uk/our-work/what-is-poverty

Kenny, C. (2002). Information and communication technologies for direct poverty alleviation: costs and benefits. Development policy review, 20(2), 141-157.

Kitzinger, J. (1994). The methodology of focus groups: The importance of interaction between research participants. Sociology of Health \& IIIness, 16(1), 103-121.

Levy, D. M. (2007). No time to think: Reflections on information technology and contemplative scholarship. Ethics and information technology, 9(4), 237-249.

Lievrouw, L. A., \& Farb, S. E. (2003). Information and equity. Annual review of information science and technology, 37(1), 499-540.

Lloyd, A., A. Kennan, M., Thompson, K. M., \& Qayyum, A. (2013). Connecting with new information landscapes: information literacy practices of refugees. Journal of Documentation, 69(1), 121-144.

Lyon Declaration. (2014) On access to information and development, Available at: https://www.lyondeclaration.org/ Accessed 28/04/18

MacDonald, J., Peter Bath and Andrew Booth. "Information overload and information poverty: challenges for healthcare services managers?." Journal of Documentation 67.2 (2011): 238-263.

Malawi demographic and health survey 2010. Zomba, National Statistical Office and Calverton, Maryland, ICF Macro, 2011. Available at: http://dhsprogram.com/pubs/pdf/FR247/FR247.pdf 
Marcella, R. (2018) The use of self moderated focus groups to gather exploratory data on information beliefs and their impact on information seeking behaviour, Library \& Information Science Research, 40 (1), 45-52.

Marcella, R., Baxter, G., \& Moore, N. (2002). An exploration of the effectiveness for the citizen of Web-based systems of communicating UK parliamentary and devolved assembly information. Journal of Government Information, 29(6), 371-391.

Martin, C. A. (1973). There's more than one way to skin a cat: the issue of heredity and antiegalitarian research. Journal of Negro Education, 42(4), 559-569.

Mayer, S., E. (2003). What is a "Disadvantaged Group?" Minneapolis: Effective Communities Project.

Maxcy, S. J. (2003). Pragmatic threads in mixed methods research in the social sciences: The search for multiple modes of inquiry and the end of the philosophy of formalism. Handbook of Mixed Methods in Social and Behavioral Research, 51-89.

Morgan, D. L. (2013). Focus groups as qualitative research. Planning, 10 (9781412984287), n4.

Mossberger, K., Tolbert, C. J., \& McNeal, R. S. (2007). Digital citizenship: the Internet, society, and participation. MIT Press.

Muddiman, D., Durrani, S., Dutch, M., Linley, R., Pateman, J., \& Vincent, J. (2000). Open to all? The public library and social exclusion (Vol. 1). London: Resource: The Council for Museums, Archives and Libraries.

Murdock, G., \& Golding, P. (1989). Information poverty and political inequality: Citizenship in the age of privatized communications. Journal of Communication, 39(3), 180-195.

Neter, E., and Brainin, E.. (2012) eHealth literacy: extending the digital divide to the realm of health information. Journal of medical Internet research 14 (1) 30pp.

Norris, P. (2001). Digital divide: civic engagement, information poverty, and the Internet worldwide. Cambridge University Press.

OECD. (2017) DAC List of ODA [official development assistance] Recipients. Available at: http://www.oecd.org/dac/financing-sustainable-development/development-financestandards/DAC List ODA Recipients2014to2017 flows En.pdf Accessed: 26/04/18

Osiobe, S. A. (1989). Health information imperatives for third world countries. Social Science \& Medicine, 28(1), 9-12.

Pandita, N., Singh, S., \& Dash, S. S. (2008). Barriers to equitable access to quality health information with emphasis on developing countries. Rockefeller foundation.

Parker, E. B. (1976). Social implications of computer/telecoms systems. Telecommunications Policy, 1(1), 3-20. 
Parker, E. B., \& Dunn, D. A. (1972). Information technology: its social potential. Science, 176(4042), 1392-1399.

Pateman, J. (1999). Social exclusion: an international perspective on the role of the State, communities and public libraries in tackling social exclusion. Journal of Information Science, 25(6), 445-463.

Pickard, A. (1998). The impact of access to electronic and digital information resources on learning opportunities for young people: a grounded theory approach. Information Research, 4(2).

Reason, J. (2000). Human error: models and management. BMJ: British Medical Journal, 320(7237), 768.

Saracevic, T. (1986). Processes and problems in information consolidation. Information Processing \& Management, 22(1), 45-60.

Sawaya, J., Maswabi, T., Taolo, R., Andrade, P., Moreno Grez, M., Pacheco, P., \& Jeżowska, J. (2011). Advocacy and evidence for sustainable public computer access: experiences from the Global Libraries Initiative. Library Review, 60(6), 448-472.

Scheeder, D. (2018) Innovation and interconnectivity for social development: intervention at UN Commission for Social Development. Speech given to the UN on 30 January, 2018.

Available at: https://www.ifla.org/files/assets/hq/topics/librariesdevelopment/documents/dscheeder csocd56 speech.pdf Accessed 8th February 2018.

Selwyn, N. (2002). 'E-stablishing'an inclusive society? Technology, social exclusion and UK government policy making. Journal of Social Policy, 31(1), 1-20.

STATISTA. (2018). Mobile internet usage worldwide: statistics \& facts. Available at: https://www.statista.com/topics/779/mobile-internet/ Accessed: 28/04/18

Stewart, D. W., \& Shamdasani, P. N. (2014). Focus groups: Theory and practice (Vol. 20). Sage publications.

Sweetland, J. H. (1993). Information poverty-Let me count the ways. Database, 16(4), 8-10.

Szumilas, M., \& Kutcher, S. (2009). Teen suicide information on the internet: a systematic analysis of quality. The Canadian Journal of Psychiatry, 54(9), 596-604.

Tenhunen, S. (2008). Mobile technology in the village: ICTs, culture, and social logistics in India. Journal of the Royal Anthropological Institute, 14(3), 515-534.

Thompson, K. M., Jaeger, P. T., Taylor, N. G., Subramaniam, M., \& Bertot, J. C. (2014). Digital Literacy and Digital Inclusion: Information Policy and the Public Library. Rowman \& Littlefield Publishers.

Torero, M., \& Von Braun, J. (Eds.). (2006). Information and communication technologies for development and poverty reduction: The potential of telecommunications. Intl Food Policy Res Inst. 
UNESCO. (2006) The situation of women and children. Available at:

https://www.unicef.org/malawi/children.html Accessed: 27/04/18

U.N. (1948) Universal Declaration of Human Rights. Available at:

http://www.un.org/en/universal-declaration-human-rights/index.html Accessed: 27/04/18

U.N. (2015) . Sustainable Development Goals: 17 goals to transform our world. Available at: http://www.un.org/sustainabledevelopment/sustainable-development-goals/ Accessed:

$27 / 04 / 18$

Van Dijk, J., \& Hacker, K. (2003). The digital divide as a complex and dynamic phenomenon. The information society, 19(4), 315-326.

Warschauer, M. (2004). Technology and social inclusion: rethinking the digital divide. MIT press.

World Health Organization (no date) . Reproductive and Women's Health. Available at: http://www.afro.who.int/en/sexual-and-reproductive-health.html Accessed: 27/04/18

Wyatt, S. et al., 2005. The digital divide, health information and everyday life. New Media \& Society, 7(2) pp. 199-218.

Yates, S. The real digital divide? Understanding the demographics of non-users and limited users of the internet: an analysis of Ofcom data. Good Things Foundation and BT. Available at: https://www.goodthingsfoundation.org/sites/default/files/researchpublications/ofcom report v4 links.pdf Accessed: 27/04/18

Yates, S. J., Kirby, J., \& Lockley, E. (2015). 'Digital-by-default': reinforcing exclusion through technology. In Defence of Welfare, 2, 158.

Yu, L. (2006). Understanding information inequality: Making sense of the literature of the information and digital divides. Journal of Librarianship and Information Science, 38(4), 229252.

Yu, L., Zhou, W., Yu, B., \& Liu, H. (2016). Towards a comprehensive measurement of the information rich and poor: based on the conceptualization of individuals as information agents. Journal of Documentation, 72(4), 614-635.Zukin, C., \& Snyder, R. (1984). Passive learning: When the media environment is the message. Public Opinion Quarterly, 48(3), 629638.

Zukin, C. \& Snyder, R. (1984). Passive learning: when the media environment is the message. The Public Opinion Quarterly, 48(3), 629-638. 